\title{
Introduction to Drones and Technology Applied to the Creative Industry. AiRT Project: An Overview of the Main Results and Actions
}

\author{
Virginia Santamarina-Campos and Marival Segarra-Oña
}

\begin{abstract}
The aim of this book is to disseminate the results and actions deployed within the H2020 European Project AiRT, Technology Transfer of RPAS (Remotely piloted aircraft systems) for the creative industries. This book collects the different approaches of the project, including the definition of the problem and needs identification, the technological aspects and the business model definition. Different experts from the industry as well as from the academic sector participated in this book by discussing the results of this highly innovative project and how it will impact on different stakeholders, from society to the creative industries, considering the economic impact that the drone sector and creative industries represent in Europe, but also how the successful process of transferring knowledge and technology is supported by the European Commission and from European Universities. This is a key factor when analysing the success of this short and very demanding project.
\end{abstract}

\footnotetext{
The original version of this chapter was revised. A correction to this chapter is available at https:// doi.org/10.1007/978-3-319-95261-1_12.

The project has received funding from the European Union's Horizon 2020 research and innovation programme under grant agreement no 732433. Reference: H2020-ICT-2016-2017. This book reflects the views of the authors and not necessary the position of the Commission.

This publication has received funding from the Program for the promotion of scientific research, technological development and innovation of the Counsel of Education, Research, Culture and Sport, Valencian Region. Reference: AORG/2018/093.

V. Santamarina-Campos $(\bowtie)$

Conserv. \& Restoration of Cult. Heritage Department, Universitat Politècnica de València,

Valencia, Spain

e-mail: virsanca@upv.es

M. Segarra-Oña

Management Department, Universitat Politècnica de València, Valencia, Spain

e-mail: maseo@omp.upv.es
} 


\section{The Content}

After providing an overview of the drones' industry history and its future evolution from a technological point of view as a prologue to the book, in this first chapter a contextualisation of the AiRT project is presented. We start by setting out the identification of the problems on which the proposal was based, its objectives, methodology and work plan development, including the main achievements. The detailed explanation of the project structure and the different work packages, its objectives and resources deployment are presented.

Then, the second chapter analyses the economic impact of the creative industry in the European Union, followed by the third chapter, that presents the study of the creative industries' needs and how their market is expanding and the demand for services related to their activities is increasing.

In the fourth chapter, the authors focus on one of the key points for SMEs for the success of tech-transfer and innovation: financing. They do so by exploring the different European instruments of financing and how they could be applied to the creative industries.

In the following chapter, successful cases where technology and creative industries shake hands are disentangled, with a special focus on the filming industry, where technology is commonly applied.

In Chapter "Storyboarding as a means of requirements elicitation and user interface design: an application to the drones' industry", the storyboarding method is introduced, along with its use as a tool for requirements elicitation, and user interface design in the drone industry is explained. The storyboards are universally understandable and provide a common ground for sharing ideas, as well as for discussing and discovering new points of view. Storytelling in this type of technology transfer projects is very innovative and highly recommended.

Chapter "Usability and experience of the creative industries, through heuristic evaluation of flight software for mapping and photogrammetry with drones" includes the analysis of 30 mesh or mosaic flight plan software programmes, in order to carry out a technical analysis related to aspects of usability and design, with the aim of optimising the design of the software. In this study, a group of experts from the consortium and SMEs from the creative industries and aviation sector participated.

In Chapter "How a cutting-edge technology can benefit the creative industries: the positioning system at work", one of the technical novelties that are integrated in final product is presented: the innovative positioning system developed by Pozyx and its application for the indoor aerial and the creative industries.

In Chapter "Indoor drones for the creative industries: distinctive features/opportunities in safety navigation", an analysis on the indoor drones' characteristics and the differences from the existing RPAS is presented, with a special focus on benefits and future opportunities for the aerial industry.

Lastly, and before the conclusions sections, the links of the industry with the public administration are studied and best practices on pilots' training are presented as an example of co-regulation.

This approach to the project, will aim to provide a framework for understanding the main innovations achieved by the AiRT project, which will be presented 
throughout this publication. In the following paragraphs the objectives of the project are disentangled, and the definition of the final user needs, as well as the final product requirements are presented in the different chapters, with the objective of spreading knowledge and helping universities and the industry with our experience.

\section{The Challenge}

The goal of AiRT project is to develop an indoor RPAS built especially for the needs of the creative industries. Currently, different types of drones do exist. However, almost all of them are designed for outdoor applications. And, the few which claim to work indoors cannot be used for professional use. With this project, we want to provide the creative industry with an easy-to-use tool that gives professional results. To do so, our final product is a drone that includes the latest technological advances: a cost-efficient, but very precise indoor positioning system and an intelligent flight control system that ensures safety.

Currently the aviation industry is experiencing an unstoppable revolution with the recent and successful introduction of drones into the mass market. The technological advances of these tools have allowed for the reduction of production costs, which have resulted in a price drop; consequently, drone use has expanded to other sectors, such as leisure, transportation and fleeting of goods, ecological surveillance, etc. (De-Miguel-Molina and Segarra-Oña 2017), thereby decentralising its military use and opening new business opportunities to industries such in the creative sector (Santamarina-Campos 2017).

Technically known as Unmanned Aerial Systems (UAS) or Unmanned Aerial Vehicles (UAV) and more recently Remotely Piloted Aircraft Systems (RPAS), these aircrafts, which operate without a human pilot on board, can be controlled either autonomously or remotely by a pilot. In this context, both outdoor photography and filming, previously reserved for large productions, have become essential resources for advertising campaigns, news on TV, filming of events, film productions or the registration of heritage sites.

As pointed out by a European expert in the field of architecture, arquitects are "super happy" with the possibility of, for example, shots in the world of architecture, which cannot be done without drones. He also mentioned that "the pictures are spectacular, the results amazing". ${ }^{1}$ On the other hand, as another expert summarised, the use of aerial images for photogrammetry has contributed through a series of significant advantages, such as greater safety for the operator, efficiency in providing millions of points and a reduction in the execution time and costs. ${ }^{2}$

Nevertheless, in the last few years, a series of events occurred that led to enormous changes in the way of understanding the RPAS market; on one hand, a large number of companies offering products and services around the drones in

\footnotetext{
${ }^{1}$ Informer 6-See Annex 1.

${ }^{2}$ Informer 13 .
} 


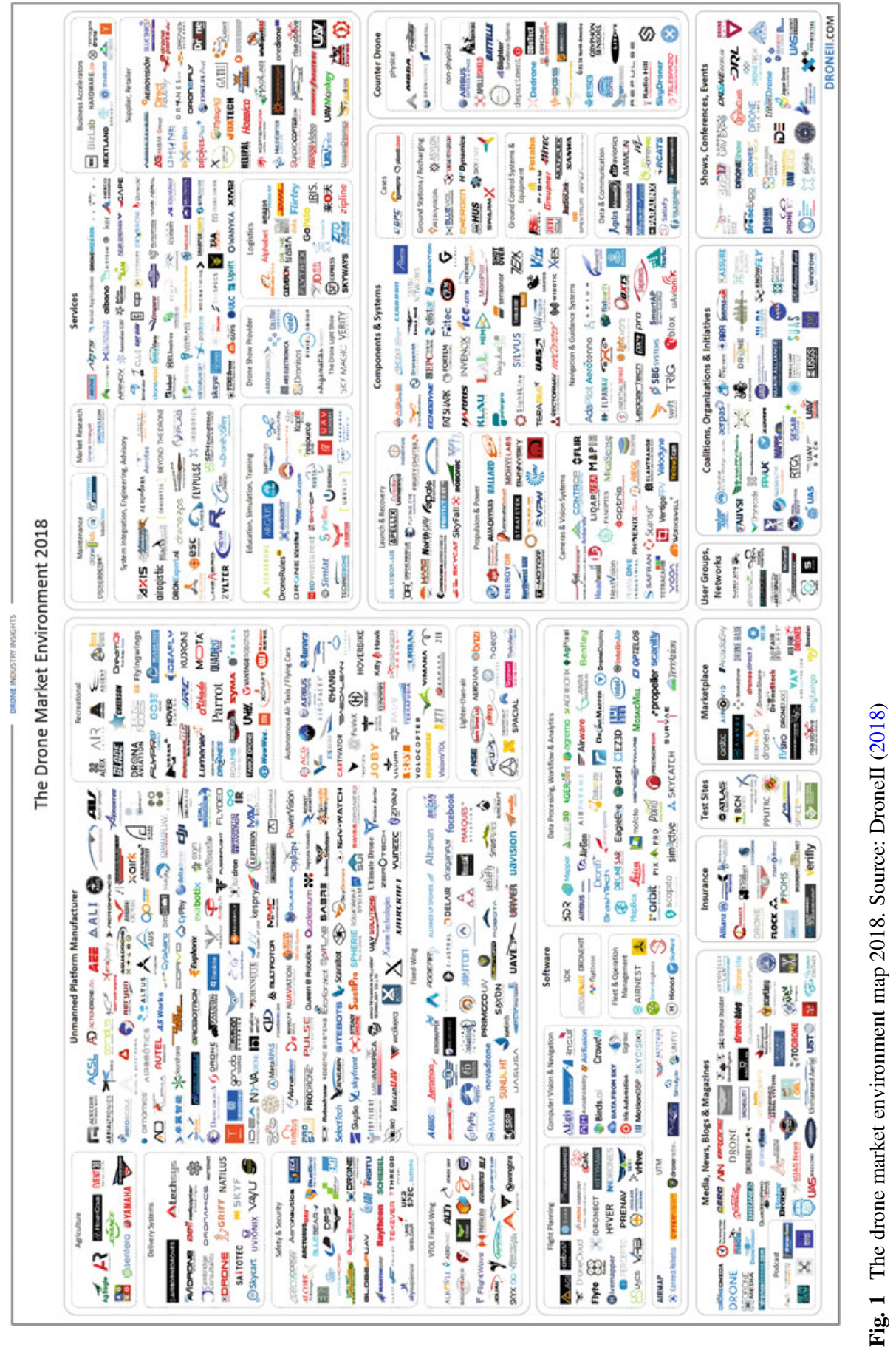


general, and electric multicopters ${ }^{3}$ in particular, have emerged, reshaping and enriching the industry (see Fig. 1). On the other hand, the consequent and hasty legislation development that regulates the use of drones at a global level, led to a reduction of the market size due to the difficulty introduced when carrying out aerial work outdoors (De-Miguel-Molina and Segarra-Oña 2017).

This scenario has turned the (initially small) drone market into a very complicated environment, with huge competition and a much reduced market, due to legislative difficulties.

Despite these circumstances, drones are an unstoppable phenomenon, and we are witnessing only the beginning of their great development. Therefore, at this point we must seek alternatives that allow new applications that facilitate the permanence and development in the market of this new sector, by offering products and services around drones.

A new market niche is indoor applications, where legislation does not apply, and the creative industries sector envisions great advantages: the creative space can be increased, a greater freedom of movement to the camera can be offered, the risks for the camera operator are reduced, invasive auxiliaries can be suppressed, and equipment is affordable. In the opinion of an expert in the field of architecture, a main limitation of filming indoors is the time required for setup. He stated that "you have little time, normally 1 or 2 days at the most, and the blue hour is 10 minutes ... then moving a crane from one place to another in a building ...you would need many devices at the same time to be able to shoot". If instead you work with a drone "it is very easy, because you move it inside and even-I don't know-you can programme it".

Despite the new advantages and creative capabilities offered by drones indoors, their use for professional applications is currently not feasible, since they lack an effective positioning system and safe design.

The vision positioning system (VPS) and the motion capture system are the main positioning systems available on the market today. The first is less expensive; however, it is conditioned by its environment, and normally they are used indoors "... to avoid shocks or obstacles rather than to position themselves ..."; the drone "... can know where it is with respect to a wall with some sensor, with respect to the floor with cameras, ... but it does not know perfectly where it is, like to programme a flight path" (extracted from interview-informant 13). The motion capture system, on the other hand, is very precise. But it needs many auxiliary devices and it is expensive, so it can only be used in big productions.

According to one of the informers of the focus group, the current problem is that there is not a safe design for drones that is adapted properly for indoor use. Thus, there is a latent risk of injury for the operator and the general public, and also a potential risk of property damage, due to the constant proximity of the drone to people and property.

\footnotetext{
${ }^{3}$ Drone is any aircraft that flies without a pilot with different types of engines and 2 or more rotors. We focus on electric engines and several rotors (multicopter).
} 


\section{The Goal}

The goal of AiRT ${ }^{4}$ project (AiRT 2017, Technology transfer of Remotely Piloted Aircraft Systems, RPAs, for the creative industry) is to develop an indoor RPAS especially built according to the needs of creative industries (CIs). The focus was on the development of an easy-to-use tool giving professional results, which will help the CIs to provide new services and improve their competitiveness within the European market. In order to achieve this objective, we retrieved information directly from the final users to finally determine that the innovative indoor RPAS should include:

- A new indoor positioning system, which has been identified as the main key element by the European experts who participated in the definition of the needs. Thus, we have an integrated Pozyx system, which is based on UWB technology that has centimetre precision in every axis.

- An intelligent flight control system, which integrates IPS, autonomous flight control and 3D reconstruction environment. As a result, the drone is user-friendly and safe, while it guarantees stable positioning in order to achieve high-quality results.

- The integration of active and passive safety measures, which constitutes one of the fundamental points not only for the safety of the operators, but also for the preservation of spaces with patrimonial value where the security margin must be extreme. Therefore, our passive security system includes a lightweight and safe design. Moreover, our active security measures include UWB technology, flight path software and an efficient safety system for drones.

- Professional camera control. The RPAS includes professional camera control with interchangeable lenses, 3-axis control, command during flight and the possibility of planning the shots. These features were highlighted by the experts in the different focus groups that the team organised. ${ }^{5}$

- Easy operation. Hence, AiRT can be controlled on different platforms such as laptops, mobiles or tablets and it allows simultaneous user control. Also, the user does not require any prior knowledge of aviation and photography. It allows an intelligent flight simulation after a $3 \mathrm{D}$ reconstruction.

- Cost-effective. The RPAS is affordable; at a sum of approximately $9000 €$ it will be cost-effective compared, for example, to renting a scaffold for $1300 €$ a day.

\footnotetext{
${ }^{4}$ Definition of AIRT, chiefly Scottish: compass point.

${ }^{5}$ Informant 20 said: “... since the auxiliary tools generate numerous restrictions, for example, the pole has many limitations, if you could stabilize the drone at a point $[\mathrm{x}]$ and then it would take the shots, it would be very important". Therefore, "if it could be located at a point and could make the 360 degrees panoramic shot ...that would be good." "The more setting options you have, the more useful everything will be, because many times you do not know the problems that you have above and if you have to fly down with the drone and then raise up again - that takes time".
} 
Our specific objectives were to analyse the needs of the creative industries, to adapt the indoor positioning system to the drone, to develop a user guide, and to adapt the pre-existing drone (model called "origami") from AeroTools, (one of the project's partners), to integrate and validate its components, to develop a demonstration with the creative industries and to propose an indoor legislation.

The initial idea was to provide the creative industries with an RPAS for interior spaces, so we can enhance their creativity, enabling them to offer new services. The final drone is expected to fulfil the needs for:

- Publicity agencies that are looking for freedom of movement so they can explore new perspectives.

- The movie industry, which is looking to reduce time and costs of auxiliaries and to develop the pre-visualisation of the storyboard, more specifically camera movements and shots.

- The photography industry that is looking for tools that allow them to explore new perspectives.

- TV production sets, which are always looking for originality and continuously and creativity exploring new techniques.

- The performing arts that are looking for dynamic structures, since their representations are itinerant.

- The video game industry that is looking for affordable and simple solutions to create more realistic video games.

- Architecture and heritage organisations that are looking for quick, simpler and less invasive solutions for supervisions, inspections and graphical surveys.

- Therefore, as previously stated, the concept of the AiRT system has been based on

- a drone for indoor spaces used by the creative industries, which has a robust, compact and lightweight structure with all necessary safety measures.

- an intelligent flight control system, which can be used by non-aviation experts on different media platforms.

\section{Approach and Methodology}

With the objective of transferring the AiRT system to the creative industries in an efficient way, the project has been developed in four interconnected phases, which are the identification of needs, the adaptation and optimisation of different technologies, the integration and validation of the system and finally the evaluation and demonstration of the system. The evaluation has been present throughout the four phases in a systematic way (see Fig. 2).

The methodology used in the development of the project has been based on Design Thinking (Both 2009; Martin 2009; Stickdorn et al. 2011; JohanssonSköldberg et al. 2013), where the participation of the end-users is present throughout the entire process (see Fig. 3). 


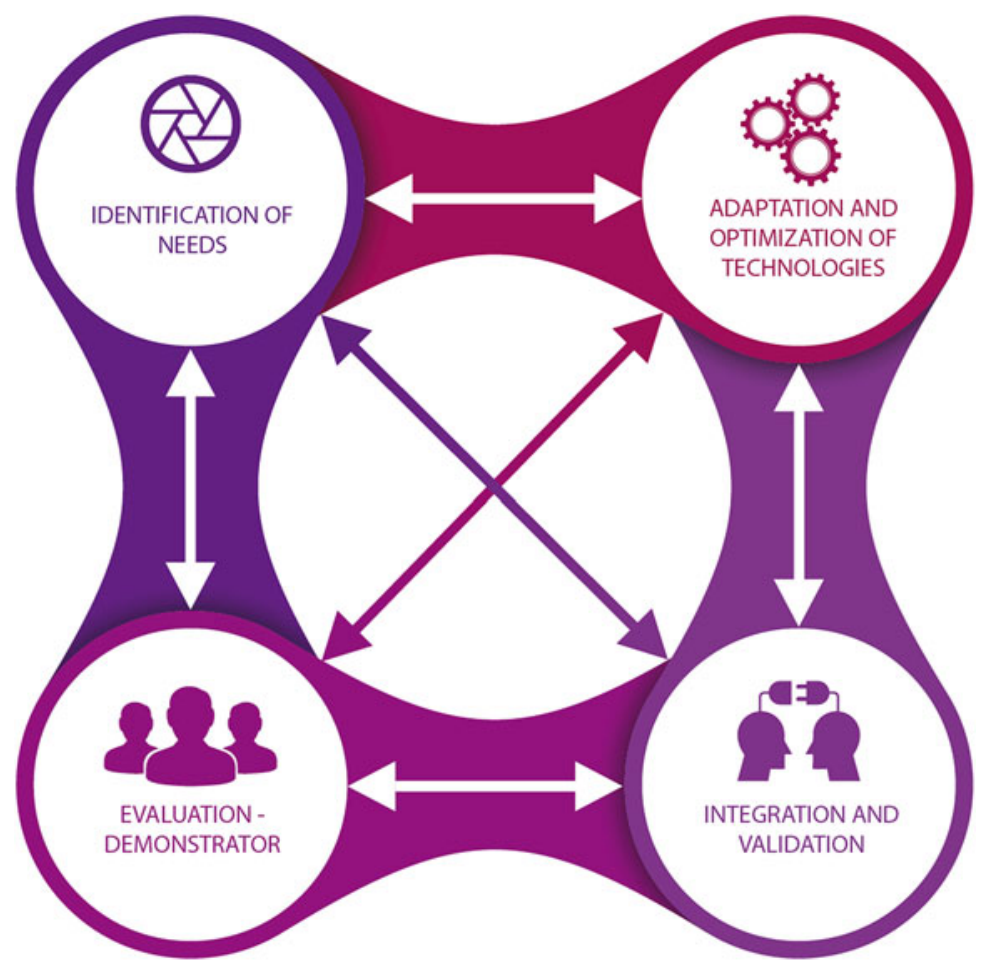

Fig. 2 Approach of AiRT in four phases. Source: Own elaboration

The use of this methodology has been aimed at understanding and providing a solution to the real needs of the creative industries, in order to align the detected needs with what is technologically feasible and commercially viable, thereby increasing their competitiveness (Brown 2009) and defining a valid business model (Osterwalder and Pigneur 2010). For this reason, the process focused on three pillars (see Fig. 4):

1. Empathise with creative industries to understand their problems and requirements.

2. Generate collaborative activities with end-users, in order to obtain creative and analytical feedback, thus creating a systematic process incorporating points of view from all stakeholders.

3. Develop prototypes that will be validated by end-users in order to identify any possible improvements before producing the final product.

Thus, five interrelated phases were developed. Interaction with end-users was always present (see Fig. 5).

We followed a participatory process of five steps, where we conducted the focus groups (Step 1). With the content analysis of the information we created some needs maps (Step 2) and then we drew the user's storyboards (Step 3). Next, we designed 


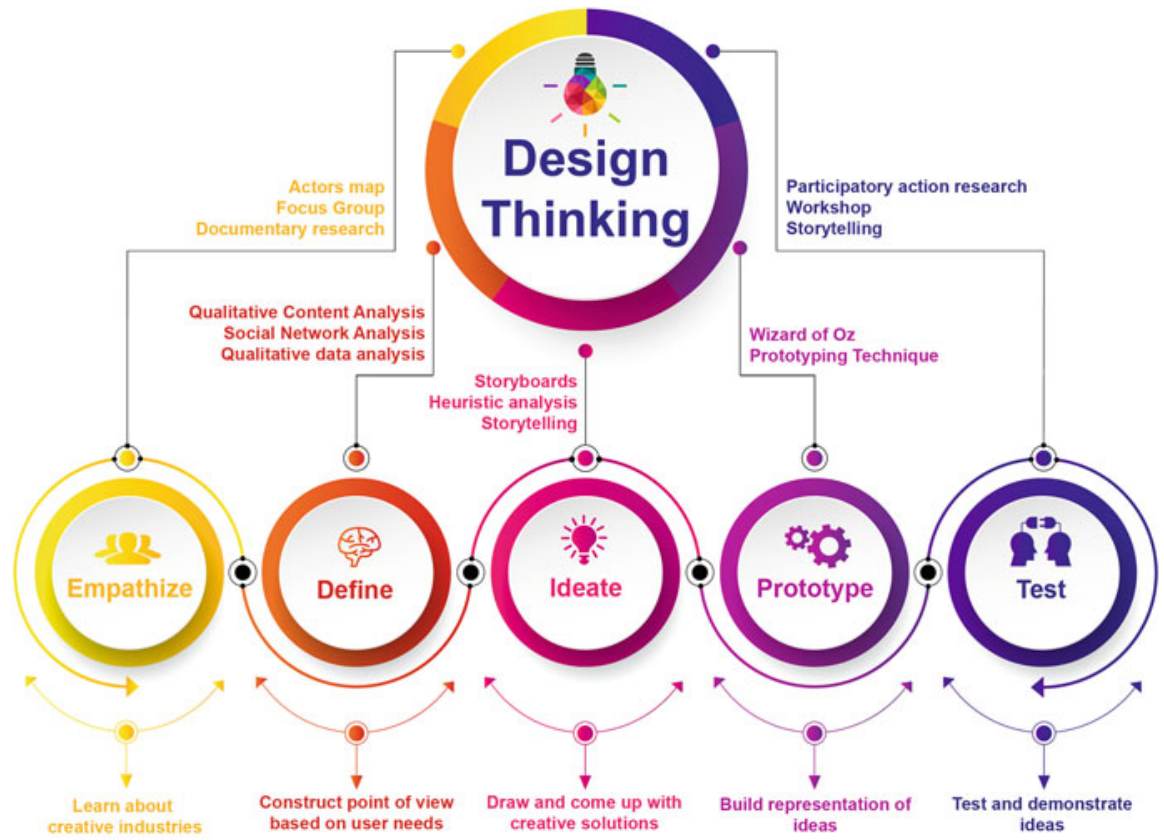

Fig. 3 Detail of the design thinking method used in the AiRT project. Source: Own elaboration, adapted from Both (2009)

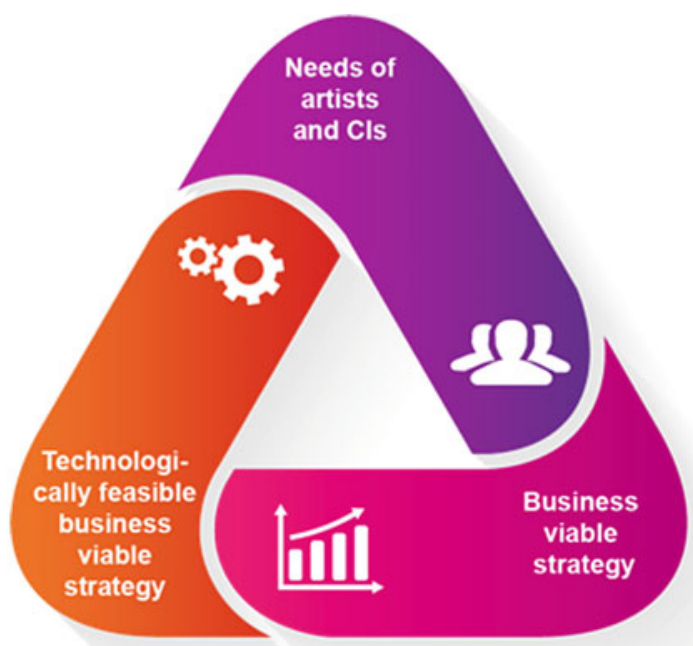

Fig. 4 The parallel requirements to be satisfied in AiRT project methodology. Source: own elaboration 


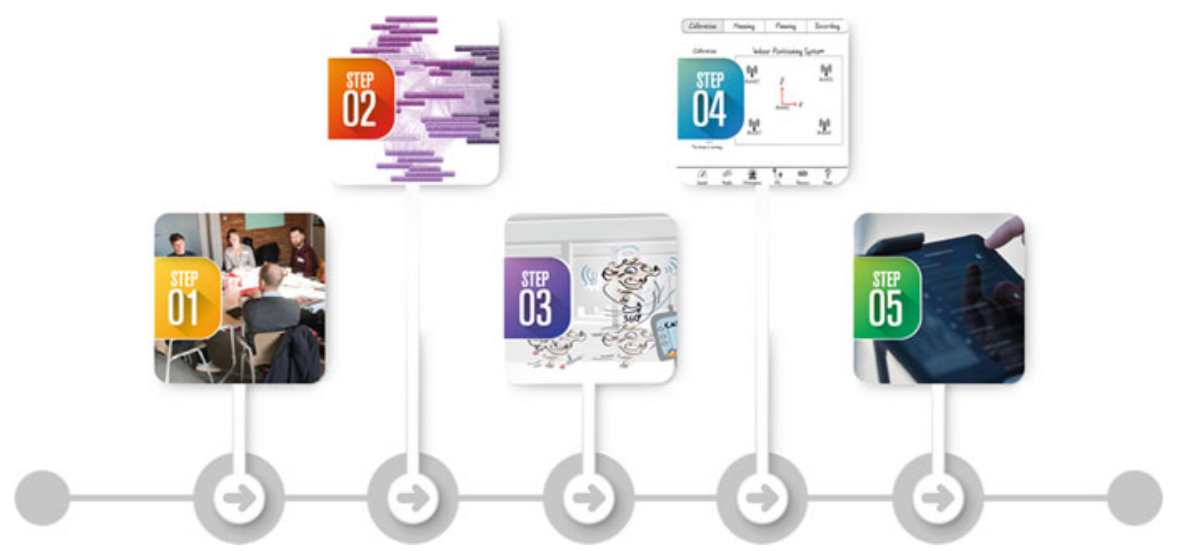

Fig. 5 Participatory process of the project. Source: Own elaboration

the software in accordance with this information (Step 4), and finally we tested the product with the same participants of the focus groups in a demonstration session, through the use of Participatory Action Research (McIntyre 2007) (Step 5).

The project began with the first step, in which a diagnosis of the needs of the creative industries was made and, after the analysis, a proposal of solutions was developed. To do so, different Service Design Tools were used. Firstly, the actors' map tool (Morelli 2007) was applied to represent who should be considered and their relations, in order to obtain a holistic and clear vision of the participants. At the same time, an analysis of ethical issues and risk analysis was carried out in order to obtain a global vision of the regulatory, safety and ethical constraints, and their causes and effects in order to overcome them with the main objective proposal, and fulfil customers' needs by accomplishing liability, technical feasibility and reliability.

The first phase of the project was called "Empathise". Three focus groups were carried out in Spain, the United Kingdom and Belgium, from which we were able to obtain information from 13 different sectors of the creative industries (40\% were drone pilots). Previously, we completed a study of the academic literature in order to identify already known barriers and facilitators; previous interesting issues to consider were deployed.

In the second phase "Define" we analysed the data using the Qualitative Content Analysis method (Mayring 2014), the Social Network Analysis, SNA method (Borgatti et al. 2009), in addition to manually coding and categorising the qualitative data. As a result, we obtained the needs analysis, the ethical problems and the risk analysis. The results obtained formed the basis for the design of the drone, the development of the European policy book (De-Miguel-Molina and SantamarinaCampos 2018) and the redefinition of the Exploitation plan (AiRT 2017).

Subsequently, from the synthesis of the obtained information in the focus group, together with the specifications included in the grand agreement, in the third phase "Ideate", written scripts were elaborated that were later transferred to graphic scripts (storyboards) (see Fig. 4). Those represented the use of the AiRT system in different 
creative scenarios, allowing communication of the main ideas in a clearer way. From the storyboards, the requirements were derived to obtain specific functionality to be implemented in the GCS software. Furthermore, from the storyboards and the heuristic evaluation (Ball and Bothma 2017) of 30 flight plan software programs, graphic design and usability aspects were defined in the GCS software. To conclude this stage, a storytelling of the history of the project was developed, with the aim of informing the creative industries and other sectors of the potential of the tool. The "Ideas" phase is the step in which the final design of the system was carried out under the objectives and conditions established in the previous phase. In this stage, both the adaptation of the indoor positioning system and the optimisation of the RPAS were developed in parallel, performing a continuous evaluation of each task.

Once the adaptation and optimisation of the parts was completed, the "Prototype" phase began, in which the integration of all the components was carried out: the positioning system, the RPAS and the graphic user interface, allowing a first implementation of the solution, through prototype testing by all project partners. Finally, the "Test" phase was carried out, in which the final evaluation of the prototype was carried out in different relevant environments in Spain, the United Kingdom and Belgium, involving the creative industries in the demonstration process by using the Participatory Action Research tool, PAR (McIntyre 2007). As a conclusion to this stage, a storytelling of the process of developing the tool was carried out for its dissemination in social networks and product presentation. And with the aim of publicising and showing the capabilities of the AiRT system to new industrial sectors, the project was completed with a demonstrative workshop designed to show the potential of the product. This phase allowed us to determine the efficiency with which the phases of the plan had been executed, and the effectiveness and efficiency of the methodologies used to cover the detected needs.

Thus, the work plan developed is characterised by the constant evaluation of the tasks and the active participation of the creative industries throughout the entire project process. This circumstance determined the need to address to the identification, the development and testing of the prototypes, which, in turn conditioned the qualitative methodology to be used. Therefore, for the identification, the focus group was proposed (Sanders and William 2002) and for the demonstrator the PAR approach was applied. The purpose of the use of this type of technique was to obtain relevant data from the key informants (creative experts) that allowed for the subsequent interpretation and analysis of the facts based on the experiences.

The use of these qualitative techniques as methodological tools is justified by the importance conferred in this project to the creative SMEs, as main protagonists and beneficiaries. Engaging these professionals from the pre-existing idea through to the generation of the final product makes sense because both the needs analysis and the demonstration were proposed from a different focus; from the classic study of the object we now turn to the subject as the object of study. This has allowed us to provide fundamental information for the improvement cycle, and, once the project is completed, helps to tackle the commercialisation phase in which the definitive equipment will be built in a successful manner. 
Both techniques were based on a script that allowed guiding of the conversations and experiences towards the topics of greatest interest that are linked to photography and filming in confined spaces. The different informants were selected based on a series of criteria and based on a geographical selection. This selection responds to the need to delimit the study area in order to carry out a comparative analysis of the creative industries in different spatial and sectoral contexts. This procedure made it possible to relate the similarities and differences obtained in each particular case, and then to establish general conclusions that allowed, in an objective way, not only the identification of the needs of each activity, but also the ability to approach a critical analysis and demonstration of the prototype with the active participation of the groups involved in the creative industries.

At the same time, the dissemination and exploitation of all the activities described above was focused on ensuring the dissemination and exploitation of the project results in an appropriate manner, facilitating a future commercialisation phase as well as the management of rights and patents among members of the consortium.

\section{The Workplan and the Main Achievements}

The workplan is composed of seven workpackages (see Fig. 6). The first one, called Management, is led by the UPV. The second one, Analysis of needs, security and risk, is Clearhead's responsibility. The third one, Adaptation and Integration of indoor positioning system, is Pozyx's task. The fourth one, RPAS design (which is already completed), and the fifth one, Integration, Validation and Demonstration, have been developed by AeroTools. The sixth one, Dissemination, is led by the UPV. And the last one, Exploitation Strategy, is led by AeroTools.

Regarding workpackage one, the biggest achievement we had is accomplishing lean management by establishing open communication, even if the consortium is interdisciplinary (see Fig. 7).

The objective has been achieved due to two fundamental aspects: on one hand, the use of the platform Basecamp ${ }^{6}$ and, on the other one, the implementation of weekly technical meetings and collaborative and interdisciplinary work sessions, with partial and weekly deadlines for the final product.

Workpackage 2 began with the three focus group activities mentioned above and included the development of the needs analysis, the ethical issues and the risk analysis. Furthermore, the information retrieved was useful for the design of the drone, the GUI (graphical user interface) and the development of advanced functionalities.

In addition, this information was key for the development of the European policy book and to enrich the Exploitation plan. The main results of this work package are included in the third chapter "Creative industries' needs: a latent demand" and in the

\footnotetext{
${ }^{6}$ https://basecamp.com/
} 


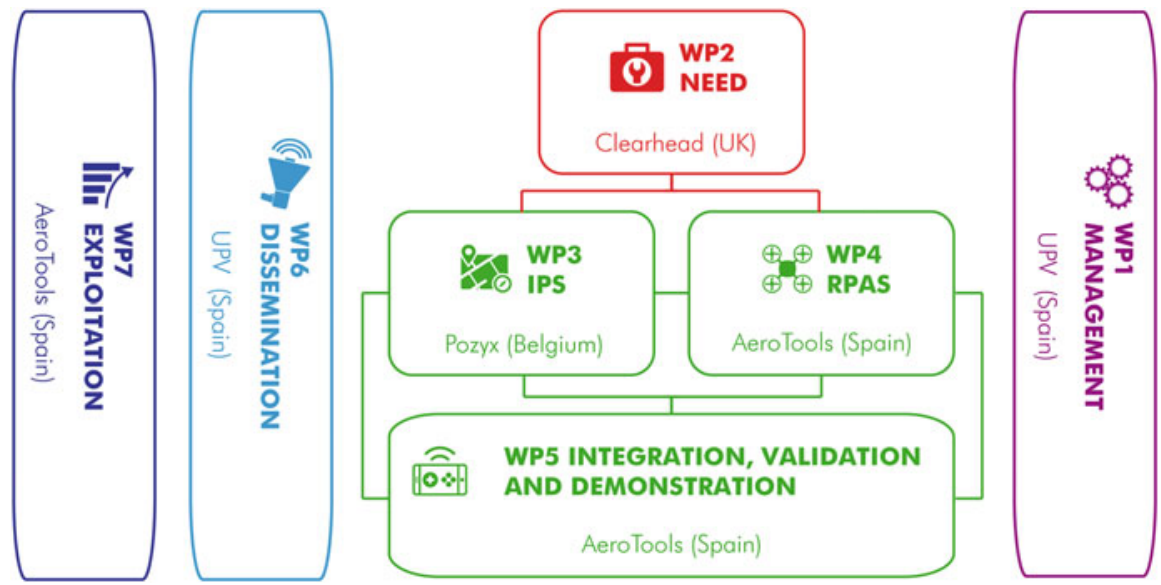

Fig. 6 Pert diagram of AiRT project. Source: Own elaboration

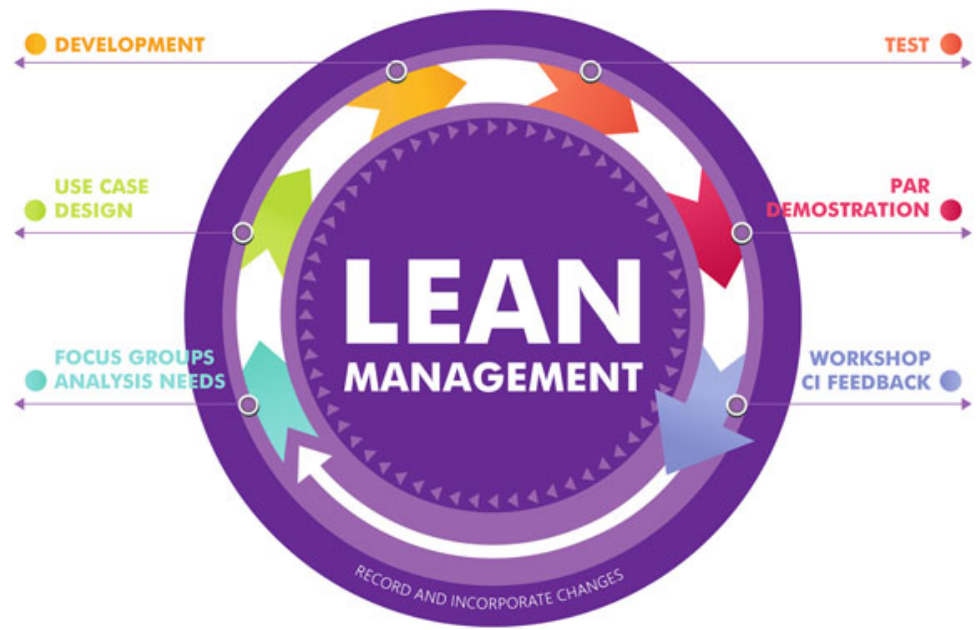

Fig. 7 Lean management. Source: Own elaboration

eighth chapter "The relationship of the industry with the public administration: co-regulation for training", where the main results obtained from the analysis of the needs, the ethical problems and the risk analysis of the creative industries are exposed.

In workpackage 3 we identified and implemented safety improvements for the indoor positioning system. We also developed methods to set up the system easily, including anchor discovery and auto-calibration. We have even implemented a fourantenna tag, which can be mounted on a drone. Furthermore, we developed 
customised algorithms for positioning, making optimal use of the four-antenna configuration. And finally, we developed a virtual environment map. The analysis and potential of this innovative indoor positioning tool will be tackled in the chapter titled "How cutting-edge technology can benefit the creative industries. The positioning system at work", where new functionalities applicable to the creative industries sector will be analysed.

In workpackage 4 the drone was redesigned in accordance to all the needs of the creative industries and the specifications in Annex 1 (part A) of the DoA, ${ }^{7}$ in the Grant Agreement no 732,433. As a result, it is safe and secure, allowing high-quality filming and optimal compromise between drone size and payload. The main challenge reached in this work package will be illustrated in the ninth chapter, titled "Indoor drones for the creative industries: distinctive features/opportunities", through an analysis of the market opportunities of indoor drones in the sector of the creative industries.

In workpackage 5 , in order to integrate all system components, the communication channels between different components have been established. An Intelligent Flight Control System was developed to control the RPAS remotely. This system is composed of the ground control system and the on-board control system and it is based on a mapping building system. All these systems can be accessed by means of the GUI.

The main methodological tool used for the development of these tasks was based on the use of storyboards, with the aim of facilitating the definition and summary of the functionalities of the AiRT system for its implementation (see example in Fig. 8). The results obtained from the use of this graphical tool will be collected in chapter seven, "Storyboarding as a means of requirements elicitation and user interface design. An application to the drones' industry".

Workpackage 6 is dedicated to the dissemination of the project results. More than 1100 people follow the progress of the project on Facebook. This was achieved through our website update activities, our work on social media, including both the professional sites (LinkedIn, Vimeo and Researchgate) and the transversal sites (known networks Facebook, Twitter, Instagram and YouTube). Moreover, project visibility is obtained through our participation in conferences, as well as the publication of several academic chapter books.

In workpackage 7, the Exploitation plan was revised by our focus groups and was complemented by an analysis of our competitors in the market. With this information and the value proposition of the prototype, AeroTools will be able to define more precisely the Exploitation plan. In chapter seven, "Indoor drones for the creative industries: distinctive features/opportunities", not only will the main innovations derived from the work package four be tackled, but also the market opportunities of the indoor drones in the sector of creative industries.

${ }^{7}$ Description of the action. 


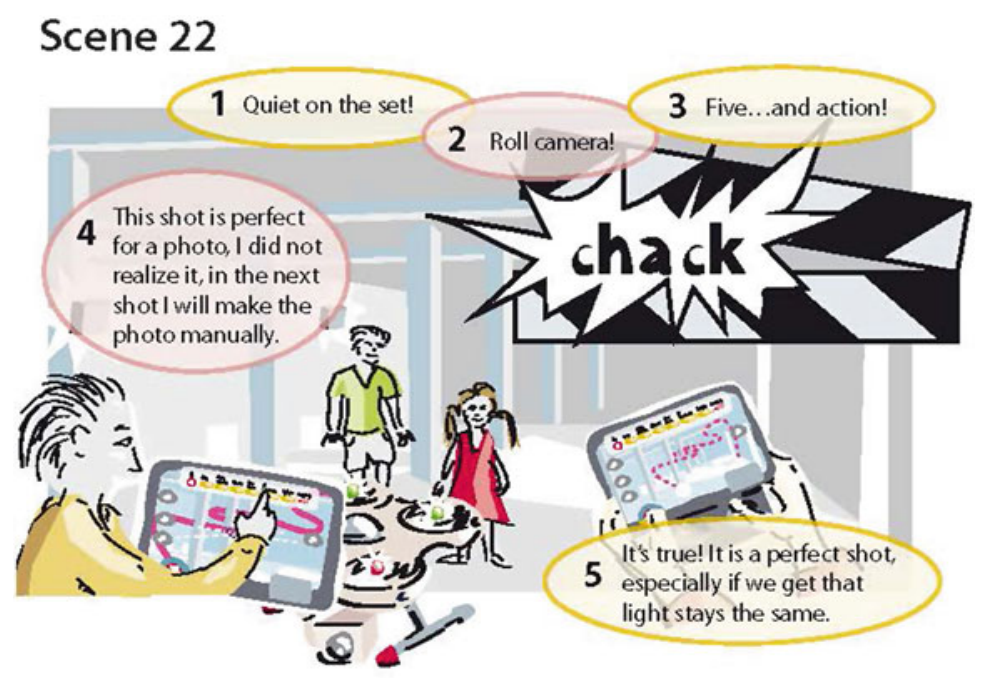

Fig. 8 Detail of the graphic script (storyboard UC00). Source: Own elaboration

\section{Conclusion}

The creative industry sector is composed mainly of SMEs. These companies find two main barriers when competing with bigger organisations: (a) obtaining economic resources for investing and, (b) being aware of the newest technological developments and having access to them.

The main objective of the European Commission Innovation Actions is to support the technological transference to the creative industries in order to increase their competitiveness by opening new markets and their set of final products and services (European Commission 2010).

In this chapter, we have summarised the main objectives, steps and achievements that the interdisciplinary European team has accomplished, fulfilling the European Commission requests. The European Commission innovative actions are short projects devoted to transfer knowledge and technology from university and specialised companies to society by means of team work and the search for a highly applied final product or service that benefits a maximum number of European SMEs.

From the Universitat Politècnica de València, the partner that manages the project, and considering society as our main stakeholder and know-how recipient, we are taking the lead on disseminating results by explaining the different aspects of the project at conferences, workshops and in an academic book with the aim of allowing companies and all interested members of the public to interact and discuss not only technical, but any other concern related to the final product and the whole project.

The dissemination actions have been complemented with a demonstration session seeking to go one step further, from the theoretical side to the hands-on activity. In 
this activity, only a reduced number of experts will participate. The benefits and high standard features of the indoor drone were tested in an incomparable site, the Principe Felipe Museum, located at the Valencia Arts and Science City, verifying the high level of acceptance that the product has among SMEs and interested stakeholders.

\section{Annex: Focus Group Informants}

\begin{tabular}{l|l|l|l|l}
\hline Informant & Profile & $\begin{array}{l}\text { Drone } \\
\text { operator }\end{array}$ & Sectors & Date \\
\hline $\mathbf{1}$ & $\begin{array}{l}\text { TV/music/movies/ } \\
\text { performing arts/publishing }\end{array}$ & No & $\begin{array}{l}\text { Publicity, TV, cinema } \\
\text { and videogames } \\
\text { sectors }\end{array}$ & February 2017 \\
\hline $\mathbf{6}$ & Design/architecture & No & $\begin{array}{l}\text { Architecture, museums } \\
\text { and heritage sectors }\end{array}$ & February 2017 \\
\hline $\mathbf{8}$ & $\begin{array}{l}\text { Antiques and museums/arts } \\
\text { \&crafts }\end{array}$ & No & $\begin{array}{l}\text { Architecture, museums } \\
\text { and heritage sectors }\end{array}$ & February 2017 \\
\hline $\mathbf{1 3}$ & $\begin{array}{l}\text { Advertising/architecture/ } \\
\text { photo }\end{array}$ & Yes & $\begin{array}{l}\text { Architecture, museums } \\
\text { and heritage sectors }\end{array}$ & February 2017 \\
\hline $\mathbf{1 4}$ & Museums/architecture & No & $\begin{array}{l}\text { Architecture, museums } \\
\text { and heritage sectors }\end{array}$ & February 2017 \\
\hline $\mathbf{1 9}$ & Movies/advertising & No & $\begin{array}{l}\text { Publicity, TV, cinema } \\
\text { and videogames } \\
\text { sectors }\end{array}$ & February 2017 \\
\hline $\mathbf{2 0}$ & $\begin{array}{l}\text { Photo/fashion/advertising/ } \\
\text { music }\end{array}$ & No & $\begin{array}{l}\text { Publicity, TV, cinema } \\
\text { and videogames } \\
\text { sectors }\end{array}$ & February 2017 \\
\hline
\end{tabular}

\section{References}

AiRT (2017) Deliverable D7.1 AiRT exploitation and business plan, IPR strategy and agreement. Non-public deliverable

Ball L, Bothma T (2017) The importance of usability evaluation when developing digital tools for a library—a case study. In: Arvola P, Hintsanen T, Kari S, Kolehma S, Luolin S, Sillanpää J (eds) Improving quality of life through information. Proceedings of the XXV Bobcatsss symposium. University of Tampere, Tampere, pp 137-142

Borgatti SP, Mehra A, Brass DJ, Labianca G (2009) Network analysis in the social sciences. Science 323(5916):892-895

Both T (2009) Bootcamp Bootleg. https://dschool.stanford.edu/resources/the-bootcamp-bootleg

Brown T (2009) Change by design. How design thinking transforms organizations and inspires innovation. Harper Collins, New York

De-Miguel-Molina M, Santamarina-Campos V (2018) Ethics and civil drones. European policies and proposals for the industry. Springer, Germany 
De-Miguel-Molina B, Segarra-Oña M (2017) The drone sector in Europe. In: De Miguel Molina M, Santamarina-Campos V (eds) Ethics and civil drones. European policies and proposals for the industry. Springer, Germany, pp 7-34

Droneii (2018) The drone market environment map 2018. Available via DRONEII. https://www. droneii.com/drone-market-environment-map-2018. Accessed 25 Jan 2018

European Commission (2010) Green paper: unlocking the potential of cultural and creative industries, COM/2010/0183 final, Brussels. http://eur-lex.europa.eu/legal-content/EN/TXT/ PDF/?uri=CELEX:52010DC0183\&from=EN. Accessed 15 Mar 2018

Johansson-Sköldberg U, Woodilla J, Çetinkaya M (2013) Design thinking: past, present and possible futures. Creat Innov Manag 22(2):121-146

Martin RL (2009) The design of business: why design thinking is the next competitive advantage. Harvard Business Press, Boston

Mayring P (2014) Qualitative content analysis: theoretical foundation, basic procedures and software solution. Available via SSOAR. http://nbn-resolving.de/urn:nbn:de:0168-ssoar395173. Accessed 15 Mar 2018

McIntyre A (2007) Participatory action research, qualitative research methods series, vol 52. Sage, Thousand Oaks

Morelli N (2007) New representation techniques for designing in a systemic perspective. In: Paper presented at design inquires. University of Arts, Crafts and Design, Stockholm, 27-30 May 2007

Osterwalder and Pigneur (2010) Business model generation. Wiley, Canada

Sanders E, William C (2002) Harnessing people's creativity: ideation and expression through visual communication. In: Langford J, McDonagh-Philp D (eds) Focus groups: supporting effective product development. Taylor and Francis, London, p 137

Santamarina-Campos V (2017) EU policies about drones. In: De Miguel Molina M, SantamarinaCampos V (eds) Ethics and civil drones. European policies and proposals for the industry. Springer, Germany, pp 35-42

Stickdorn M, Schneider J, Andrews K, Lawrence A (2011) This is service design thinking: basics, tools, cases, vol 1. Wiley, Hoboken

Open Access This chapter is licensed under the terms of the Creative Commons Attribution 4.0 International License (http://creativecommons.org/licenses/by/4.0/), which permits use, sharing, adaptation, distribution and reproduction in any medium or format, as long as you give appropriate credit to the original author(s) and the source, provide a link to the Creative Commons license and indicate if changes were made.

The images or other third party material in this chapter are included in the chapter's Creative Commons license, unless indicated otherwise in a credit line to the material. If material is not included in the chapter's Creative Commons license and your intended use is not permitted by statutory regulation or exceeds the permitted use, you will need to obtain permission directly from the copyright holder.

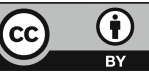

